University of Nebraska - Lincoln

DigitalCommons@University of Nebraska - Lincoln

4-15-1985

\title{
Anomalous magnetic hysteresis in an amorphous $\mathrm{Nd}_{54} \mathrm{C}_{36} \mathrm{~B}_{10}$ alloy
}

George C. Hadjipanayis

Kansas State University, hadji@udel.edu

S.H. Aly

Department of Physics, Kansas State University, Manhattan, Kansas

David J. Sellmyer

University of Nebraska-Lincoln, dsellmyer@unl.edu

Follow this and additional works at: https://digitalcommons.unl.edu/physicssellmyer

Part of the Physics Commons

Hadjipanayis, George C.; Aly, S.H.; and Sellmyer, David J., "Anomalous magnetic hysteresis in an amorphous $\mathrm{Nd}_{54} \mathrm{Co}_{36} \mathrm{~B}_{10}$ alloy" (1985). David Sellmyer Publications. 146.

https://digitalcommons.unl.edu/physicssellmyer/146

This Article is brought to you for free and open access by the Research Papers in Physics and Astronomy at DigitalCommons@University of Nebraska - Lincoln. It has been accepted for inclusion in David Sellmyer Publications by an authorized administrator of DigitalCommons@University of Nebraska - Lincoln. 


\title{
Anomalous magnetic hysteresis in an amorphous $\mathrm{Nd}_{54} \mathrm{Co}_{36} \mathrm{~B}_{10}$ alloy
}

\author{
G. C. Hadjipanayis and S. H. Aly \\ Department of Physics, Kansas State University, Manhattan, Kansas 66506 \\ D. J. Sellmyer \\ Department of Physics, University of Nebraska, Lincoln, Nebraska 68588
}

\begin{abstract}
The hysteresis and crystallization behavior of an amorphous $\mathrm{Nd}_{54} \mathrm{Co}_{36} \mathrm{~B}_{10}$ alloy have been examined over a range of temperatures. Crystallization studies show a glass transition temperature around $210^{\circ} \mathrm{C}$, two crystallization peaks at around 220 and $360^{\circ} \mathrm{C}$, and two endothermic peaks at around 530 and $600^{\circ} \mathrm{C}$, respectively. ac susceptibility measurements show an ordering temperature of $38 \mathrm{~K}$ for the amorphous phase. Four additional magnetic phases have been observed in the crystallized samples with ordering temperatures $17,45,90$, and $190 \mathrm{~K}$, respectively. Magnetic measurements on melt-spun ribbons reveal a coercivity of $6 \mathrm{kOe}$ at $4.2 \mathrm{~K}$. The coercivity at $4.2 \mathrm{~K}$ of a sample heat treated at the first crystallization temperature is increased to $8 \mathrm{kOe}$ but is reduced gradually upon annealing at higher temperatures and is only $2.5 \mathrm{kOe}$ in a sample annealed at a temperature close to the second endothermic peak.
\end{abstract}

\section{INTRODUCTION}

Metallic glasses based on rare-earth elements show a magnetic behavior ${ }^{1,2}$ which is quite different from that observed in transition-metal-metalloid glasses. The former exhibit a much larger anisotropy which leads to large coercivities at cryogenic temperatures. Although there are several model $^{3-5}$ discussing this anomalous magnetic hysteresis, there is still a confusion about the origin of the observed high coercive fields.

In this study we examine the thermal and magnetic properties of $\mathrm{Nd}_{54} \mathrm{Co}_{36} \mathrm{~B}_{10}$ in both the amorphous and crystallized state. ac susceptibility measurements are used to determine the ordering temperatures of the amorphous and crystalline phases that are present after crystallization. The hysteresis loops have been measured down to liquid helium temperature and their dependence on crystallization is examined. The observed high coercive fields are discussed in the light of various existing models.

\section{EXPERIMENT}

Samples of $\mathrm{Nd}_{54} \mathrm{Co}_{36} \mathrm{~B}_{10}$ were prepared from high-purity elements by arc-melting the constituents several times in argon atmosphere. The as-cast samples were then rapidly quenched into ribbons using the melt-spinning technique. The heat treatment of the samples was done either by using the differential thermal analyzer or by sealing the samples wrapped in Ta foils under vacuum in quartz tubes and heating them inside a furnace equipped with a temperature controller.

The crystallization studies were made with differential scanning calorimetry using a Dupont 900 system with a heating rate of $30 \mathrm{~K} / \mathrm{min}$. The hysteresis loops and high field ( $80 \mathrm{kOe}$ ) magnetization measurements were made at cryogenic temperatures using a vibrating sample magnetometer equipped with a vari-temp Janis dewar. The magnetic susceptibility was measured with an ac technique in a rms field of $0.01 \mathrm{Oe}$ and a frequency of $280 \mathrm{~Hz}$.

\section{RESULTS}

Figure 1 shows the crystallization data on an asquenched $\mathrm{Nd}_{54} \mathrm{Co}_{36} \mathrm{~B}_{10}$ sample using the differential scanning calorimetry (DSC) method. A glass transition temperature is observed at about $210^{\circ} \mathrm{C}$, two sharp exothermic peaks around 220 and $360^{\circ} \mathrm{C}$, and two endothermic peaks at about 530 and $600^{\circ} \mathrm{C}$, respectively. The exothermic peaks are characteristic of the crystallization of the amorphous phase.

The hysteresis loops and magnetization curves of an amorphous sample measured at cryogenic temperatures are shown in Fig. 2. A coercive force of about $6 \mathrm{kOe}$ is observed at $4.2 \mathrm{~K}$. The variation of $H_{c}$ with temperature as deduced from Fig. 2 is shown in Fig. 3. The coercive force decreases rapidly with increasing temperature and is only about 250 $\mathrm{Oe}$ at $25 \mathrm{~K}$ which is well below the ordering temperature

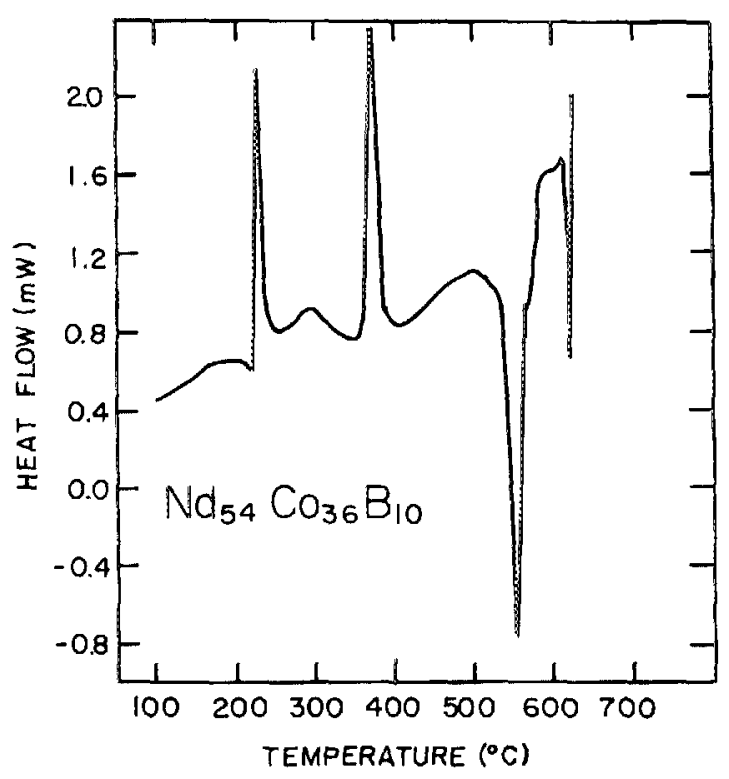

FIG. 1. Differential scanning calorimetry data on as-quenched $\mathrm{Nd}_{54} \mathrm{Co}_{36} \mathrm{~B}_{10}$ ribbons. 


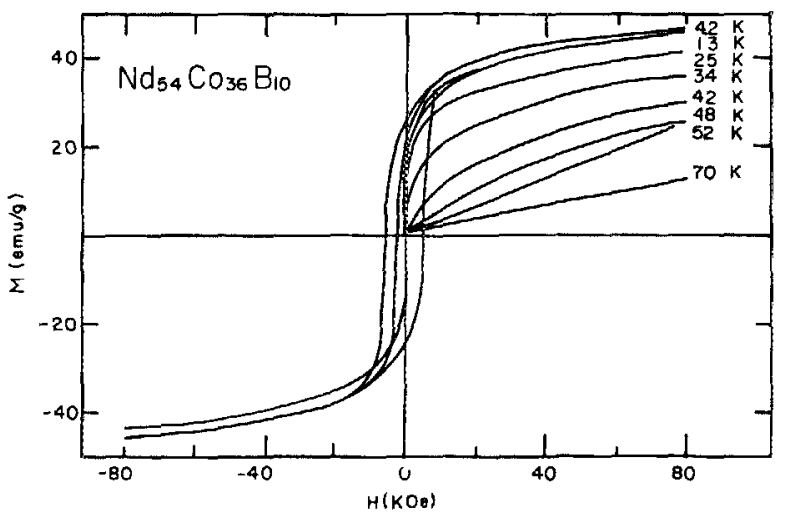

FIG. 2. Magnetization curves and hysteresis loops of amorphous $\mathrm{Nd}_{54} \mathrm{CO}_{36} \mathrm{~B}_{10}$ ribbons.

estimated to be around $40 \mathrm{~K}$. An attempt was made to study the effect of heat treatment on the magnetic properties of ribbons. Four melt-spun samples were heat treated in argon gas for $15 \mathrm{~min}$ at temperatures of $240,370,550$, and $630^{\circ} \mathrm{C}$, respectively which are close to the peaks observed in the DSC studies. Figure 4 shows the variation of $H_{c}$ measured at $4.2 \mathrm{~K}$ with the annealing temperature. The coercive force is increased to $8 \mathrm{kOe}$ for a sample heat treated at the first crystallization temperature and then is decreased upon annealing at higher temperatures reaching only the value of $2.5 \mathrm{kOe}$ in a sample heat treated at a temperature around the second. endothermic peak.

ac susceptibility measurements have been performed on amorphous as well as heat-treated ribbons. The as-quenched sample exhibit a single sharp peak at $38 \mathrm{~K}$ (Fig. 5) which is close to that observed in the amorphous $\mathrm{Nd}_{60} \mathrm{Co}_{40}$ ribbons. ${ }^{8}$ After the first crystallization, two new phases are formed with ordering temperatures $17 \mathrm{~K}$ and $45 \mathrm{~K}$. At the second crystallization these two crystalline phases and the amorphous phase disappear and two other phases are formed with ordering temperatures around 90 and $190 \mathrm{~K}$. Further an-

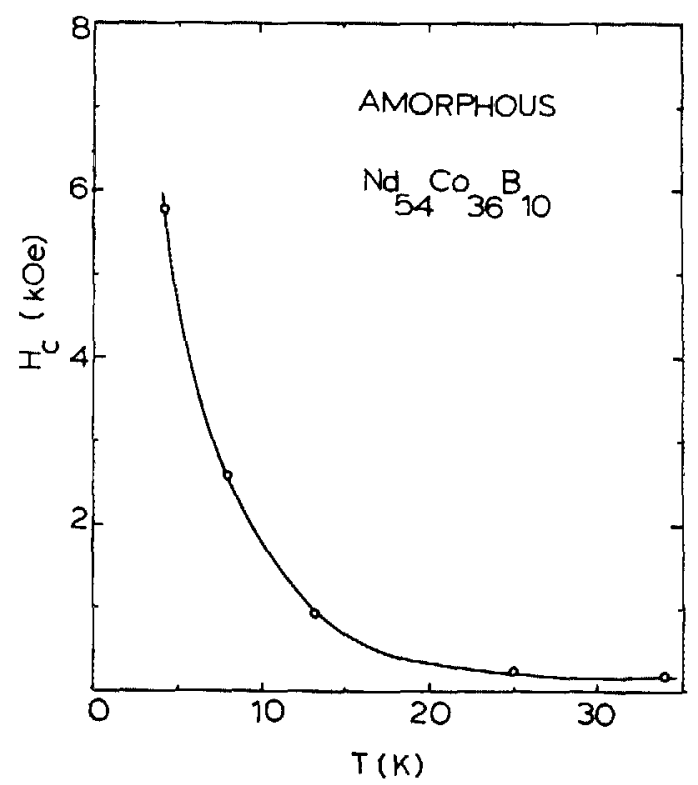

FIG. 3. Temperature dependence of coercivity in an amorphous sample.

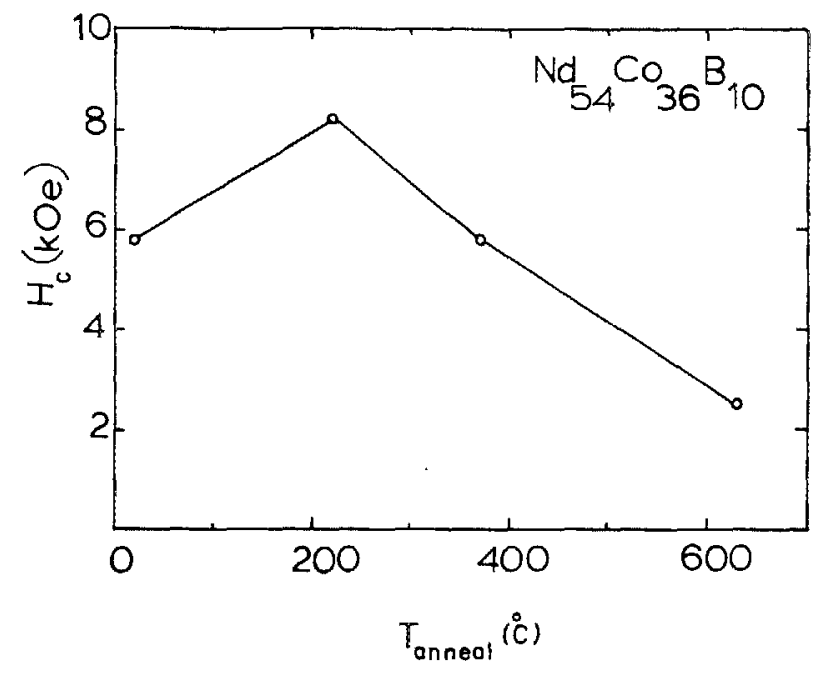

FIG. 4. Coercive force as function of annealing temperature.

nealing at $630^{\circ} \mathrm{C}$ resulted in the appearance of a new phase with an ordering temperature about $115 \mathrm{~K}$ (Table I).

\section{DISCUSSIOA}

The high-field magnetization measurements on the melt-spun ribbons at different temperatures showed that a field of $80 \mathrm{kOe}$ is not enough to saturate the sample indicating the presence of a large anisotropy. The law of approach to saturation ${ }^{6}$ is used to estimate both the saturation magnetization $M_{s}$ and the anisotropy constant $K$ at $4.2 \mathrm{~K}$. The values of $48 \mathrm{emu} / \mathrm{g}$ and $1.2 \times 10^{7} \mathrm{erg} / \mathrm{cm}^{3}$ have been obtained for $M_{s}$ and $K$, respectively. The high-field susceptibility appears to be the same at different temperatures and this suggests that the anisotropy does not change much with temperature in the temperature range studied.

In order to determine the mechanism leading to the observed magnetic hysteresis in the amorphous samples an attempt is made to interpret the experimental data in the light of some of the existing models. ${ }^{3-5}$ The single domain

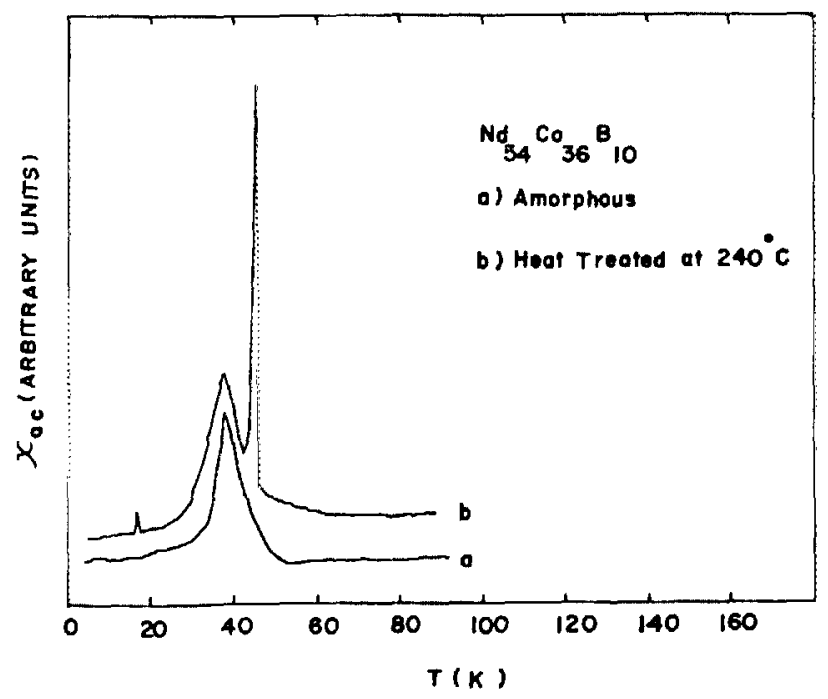

FIG. 5 . ac susceptibility measurements on an amorphous sample and a crystallized sample heat treated at $240^{\circ} \mathrm{C}$ for $15 \mathrm{~min}$. 
TABLE I. Ordering temperatures of magnetic phases determined by ac susceptibility measurements on melt-spun and crystallized samples.

\begin{tabular}{ll}
\hline \hline Heat Treatment & Ordering Temperature $(\mathrm{K})$ \\
\hline As-quenched & 38 \\
15 min at $240^{\circ} \mathrm{C}$ & 17,45 \\
15 min at $370^{\circ} \mathrm{C}$ & 90,190 \\
15 min at $630^{\circ} \mathrm{C}$ & 115 \\
\hline
\end{tabular}

particle theory ${ }^{3}$ predicts a coercive force $H_{\mathrm{c}}$ for noninteracting single domain particles equal to $K / M_{s}$. After substituting the values determined from the law of approach to saturation a value of $H_{c}=36 \mathrm{kOe}$ is found which is much larger than the value obtained by extrapolating the data of Fig. 3 to $T=0$ which is only $\sim 12 \mathrm{kOe}$. The random anisotropy model of Callen et al. ${ }^{4}$ took into account the interaction between the domains and showed that the exchange interaction can cause a decrease in the coercivity and an increase in the reduced remanence up to the value of 1. From the observed reduced remanence one can find the value of the exchange interaction and use it to predict $H_{c}$. A reduced remanent value of $\sim 0.58$ was found for the amorphous ribbon at $4.2 \mathrm{~K}$ leading to a value of $H_{c}=27 \mathrm{kOe}$ which is still larger than the experimentally determined value. A domain-wall pinning model by $\mathrm{Paul}^{5}$ has taken into account the difference between the magnetic properties of the magnetic matrix and defect and predicted the coercivity as a function of the dimensionless constants $E$ and $F$ where $E=A_{2} K_{2} / A_{1} K_{1}$, and $F=A_{2} M_{2} / A_{1} M_{1}, K$ is the anisotropy constant, $A$ is the exchange constant, $M$ is the magnetization and the subscripts 1 and 2 refer to the matrix and defect, respectively. The estimated value of coercivity at $T=0 \mathrm{~K}$ can be explained with Paul's model using values for $E$ and $F$ in the range of 0.25 0.50 assuming a defect size equal to the domain wall thickness. These values are not very unreasonable for amorphous magnetic materials where one expects large fluctuations in anisotropy and exchange interactions.

The shape of the ac susceptibility peaks provides infor- mation about the kind of magnetic phases present in the sample. ${ }^{7}$ The sharp ac peaks observed in the as-quenched samples may indicate sperimagnetic type of ordering. This is in contrast to the leveling off of ac observed below $T_{C}$ for ferromagnetic type transitions. The phases with ordering temperatures of 17 and $115 \mathrm{~K}$ may be associated with $\mathrm{Nd}$ and $\mathrm{NdCO}_{2}$, respectively. The higher Curie temperature phase of $190 \mathrm{~K}$ has been also observed in Nd-Co alloys and has been associated with a Nd-Co oxide. ${ }^{8}$ The phase with the ordering temperature of $45 \mathrm{~K}$ cannot be identified with any of the existing phases in the Nd-Co system and it is probably a ternary Nd-Co-B phase. This phase may be highly anisotropic as indicated from the increase in coercivity after the first crystallization.

The influence of crystallization on hysteresis is presently studied more analytically. Lorentz microscopy studies will be made down to cryogenic temperatures to verify the domain wall pinning hypothesis and identify the defect responsible for the observed hysteresis.

\section{ACKNOWLEDGMENTS}

We are grateful to National Science Foundation for their financial assistance under Grant No. DMR 83-04865 and to the Research Corporation.

'R. W. Cochrane, R. Harris, and M. J. Zuckermann, Phys. Rept. 48, 1 (1978); J. J. Rhyne, in Handbook of the Physics and Chemistry of RareEarths, edited by K. A. G. Schneider and L. Eyring (North-Holland, Amsterdam, 1979), p. 259.

2J. A. Gerber, D. J. Miller, and D. J. Sellmyer, J. Appl. Phys. 49, 1699 (1978); G. Hadjipanayis, D. J. Sellmyer, and B. Brandt, Phys. Rev. B 23, 3349 (1981).

${ }^{3}$ E. C. Stoner and E. P. Wohlfarth, Philos. Trans. R. Soc. Sect. A 240, 599 (1948).

${ }^{4}$ E. Callen, Y. J. Liu, and J. R. Cullen, Phys. Rev. B 16, 263 (1977)

${ }^{5}$ D. I. Paul, J. Appl. Phys. 53, 1649 (1982)

'S. Chikazumi, Physics of Magnetism (Wiley, New York, 1964).

${ }^{7}$ S. G. Cornelison and D. J. Sellmyer, Phys. Rev. B 30, 2845 (1984).

${ }^{8}$ C. P. Wong, K. Gudimetta, B. Dale, and G. C. Hadjipanayis (these proceedings) 